\title{
Commentary: We have mastered off-pump coronary artery bypass grafting technique, but not the indications for it
}

\author{
Mario Gaudino, MD, and Berhane Worku, MD
}

\author{
From the Department of Cardiothoracic Surgery, Weill Cornell Medical Center, New York, NY. \\ Disclosures: Authors have nothing to disclose with regard to commercial support. \\ Received for publication April 8, 2019; accepted for publication April 8, 2019; available ahead of print May 15 , \\ 2019. \\ Address for reprints: Mario Gaudino, MD, Department of Cardiothoracic Surgery, Weill Cornell Medical Center, \\ 525 E 68th St, M-404, New York, NY 10065 (E-mail: mfg9004@med.cornell.edu). \\ J Thorac Cardiovasc Surg 2020;159:1305-6 \\ $0022-5223 / \$ 36.00$ \\ Copyright (C) 2019 by The American Association for Thoracic Surgery \\ https://doi.org/10.1016/j.jtcvs.2019.04.027
}

Off-pump coronary artery bypass grafting (OPCAB) has been associated with reductions in bleeding complications, ${ }^{1-3}$ acute kidney injury (AKI), ${ }^{1,3}$ and stroke ${ }^{4}$ relative to on-pump coronary artery bypass grafting, but these reductions come at the cost of more incomplete revascularization, ${ }^{1,2,4}$ lower graft patency, ${ }^{2}$ and greater need for repeat revascularization, ${ }^{1,4}$ with no difference in survival. ${ }^{1,2,4}$ It has been suggested that the lack of a mortality benefit in these studies is a result of their inclusion of a population of patients at low ${ }^{2}$ to intermediate ${ }^{1}$ risk. Puskas and associates ${ }^{5}$ stratified patients by Society of Thoracic Surgeons predicted risk of mortality score and found that OPCAB was associated with significant reductions in operative mortality in higher-risk patients with a Society of Thoracic Surgeons score greater than $2.5(3.2 \%$ vs $6.7 \% ; P<.001)$, whereas no difference was noted in lower risk patients. The question remains, should OPCAB be looked at as a less invasive revascularization option for patients at high risk, even at the cost of less complete revascularization? Studies assessing the benefits of OPCAB in patients at particular risk for certain postoperative complications are therefore warranted.

In this issue of the Journal, Rocha and colleagues ${ }^{6}$ used the CorHealth Ontario Cardiac Registry to identify retrospectively 7782 patients with "moderate" renal failure, defined as estimated glomerular filtration rate of 30 to $59 \mathrm{~mL} / \mathrm{min}$, who were undergoing OPCAB versus onpump coronary artery bypass grafting. After propensity matching, OPCAB was associated with a lower rate of inhospital renal failure requiring hemodialysis $(1.2 \%$ vs $2.9 \% ; P<.01)$, but this effect was lost by 30 days. There were no differences in perioperative mortality, 8-year mortality, or progression to permanent dialysis $(7 \%$ vs $7 \%$; $P=.74) .{ }^{6}$ Strengths of the current study include its use of a large multicenter registry with adequate powering to allow a robust propensity analysis including socioeconomic variables such as income and location of residence, likely surrogates for degree of preoperative medical optimization. Limitations include a lack of data on surgeon experience,

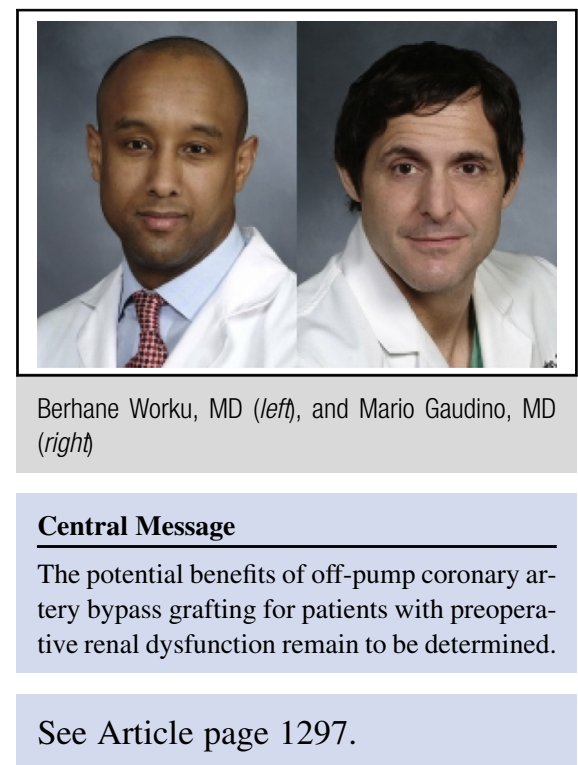

which has been clearly demonstrated to correlate with outcomes after OPCAB. ${ }^{7}$ A major limitation is a lack of granular data, including individual patient creatinine levels, allowing assessment of more subtle degrees of AKI. In addition, the definition of "moderate" renal failure, with an average creatinine of $126 \mu \mathrm{mol} / \mathrm{L}(1.43 \mathrm{mg} / \mathrm{dL})$, included mainly patients at low risk for significant postoperatively renal dysfunction regardless of CABG strategy. This likely explains the very short-lived difference in in-hospital renal outcomes.

A potential reduction of the risk of renal failure with the use of OPCAB has been suggested, but not proved. In the randomized Coronary Artery Bypass Surgery Off or On Pump Revascularization Study, ${ }^{1}$ OPCAB was associated with a reduced incidence of 30-day AKI, as defined by the Acute Kidney Injury Network criteria (stage 1, increase in creatinine $\times 1.5$ from baseline or increase of $>0.3 \mathrm{mg} / \mathrm{dL}$ within 48 hours; hazard ratio $0.87 ; P=.01$ ). In a substudy of the Coronary Artery Bypass Surgery Off or On Pump Revascularization Study that assessed short- and longterm effects on renal function, ${ }^{8}$ no difference was noted at 1 year, even in the subgroup with preoperative chronic renal insufficiency (estimated glomerular filtration rate $<60 \mathrm{~mL} /$ $\min / 1.73 \mathrm{~m}^{2}$ ). In the randomized German Off-Pump Coronary Artery Bypass Grafting in Elderly Patients Study, which included only patients older than 75 years, ${ }^{4}$ no differences in 30-day or 1-year rates of renal failure requiring 
hemodialysis were noted between the OPCAB and onpump coronary artery bypass grafting groups. In a substudy of the German Off-Pump Coronary Artery Bypass Grafting in Elderly Patients Study that assessed short-term effects of OPCAB on renal function, ${ }^{3}$ no difference was noted in 30day rates of AKI, as defined by the Acute Kidney Injury Network criteria, regardless of CABG strategy, even in the subgroup with preoperative chronic renal insufficiency (estimated glomerular filtration rate $<60 \mathrm{~mL} / \mathrm{min} / 1.73 \mathrm{~m}^{2}$ ). In the Department of Veteran Affairs Randomized On/Off Pump Bypass Study, ${ }^{2}$ no difference was noted in 30-day rates of renal failure requiring hemodialysis. A smaller trial that randomly allocated only patients with preoperative renal insufficiency (glomerular filtration rate $<60 \mathrm{~mL} / \mathrm{min} /$ $1.73 \mathrm{~m}^{2}$ ) demonstrated reduced rates of short-term (5 days) AKI with OPCAB, ${ }^{9}$ with no assessment of longer-term outcomes. In a retrospective study of more than 2000 patients from 2 hospitals in Taiwan, ${ }^{10}$ OPCAB was associated with a reduced incidence of short-term (in-hospital) renal failure requiring dialysis in patients with severe renal insufficiency (glomerular filtration rate $<30 \mathrm{~mL} / \mathrm{h}$ ), although this effect was lost after controlling for preoperative renal function. No difference was seen in long-term (4-year follow-up). Interestingly, in a much larger retrospective study of more than 38,000 patients from the Japanese Cardiovascular Surgery Database, ${ }^{11}$ OPCAB was associated with a reduced incidence of short-term (30 day/in-hospital) renal failure requiring dialysis and reduced mortality in patients with severe renal insufficiency (glomerular filtration rate $<30 \mathrm{~mL} /$ $\min / 1.73 \mathrm{~m}^{2}$ ), and this relationship held after risk adjustment, including inverse probability of treatment weighting.

The current study of Rocha and colleagues ${ }^{6}$ suggests that for patients with "moderate" renal dysfunction, immediate postoperative renal function is improved with OPCAB, but this effect is lost by 30 days, with no detectable difference in the long term. It therefore seems rational to hypothesize that in a group of patients with more significant renal dysfunction, OPCAB will demonstrate greater long-term benefits. In the last 3 decades, the pendulum has swung to and fro with regard to OPCAB, and it is still swinging. It is clear that mastery of this more challenging technique may be achieved by dedicated surgeons. What is not clear is what group of patients this mastery may benefit the most.

\section{References}

1. Lamy A, Devereaux PJ, Prabhakaran D, Taggart DP, Hu S, Paolasso E, et al. Offpump or on-pump coronary-artery bypass grafting at 30 days. $N$ Engl J Med. 2012;366:1489-97.

2. Shroyer AL, Grover FL, Hattler B, Collins JF, McDonald GO, Kozora E, et al; Veterans Affairs Randomized On/Off Bypass (ROOBY) Study Group. Onpump versus off-pump coronary-artery bypass surgery. $N$ Engl J Med. 2009; 361:1827-37.

3. Reents W, Hilker M, Börgermann J, Albert M, Plötze K, Zacher M, et al. Acute kidney injury after on-pump or off-pump coronary artery bypass grafting in elderly patients. Ann Thorac Surg. 2014;98:9-15.

4. Diegeler A, Börgermann J, Kappert U, Breuer M, Böning A, Ursulescu A, et al; GOPCABE Study Group. Off-pump versus on-pump coronary-artery bypass grafting in elderly patients. $N$ Engl J Med. 2013;368:1189-98.

5. Puskas JD, Thourani VH, Kilgo P, Cooper W, Vassiliades T, Vega JD, et al. Offpump coronary artery bypass disproportionately benefits high risk patients. Ann Thorac Surg. 2009;88:1142-7.

6. Rocha RV, Yanagawa B, Hussain MA, Tu JV, Fang J, Ouzounian M, Cusimano RJ. Off-pump versus on-pump coronary artery bypass grafting in moderate renal failure. J Thorac Cardiovasc Surg. 2020;159:1297-304.e2.

7. Gaudino M, Benedetto U, Bakaeen F, Rahouma M, Tam DY, Abouarab A, et al. Off- versus on-pump coronary surgery and the effect of follow-up length and surgeons' experience: a meta-analysis. J Am Heart Assoc. 2018;7:e010034.

8. Garg AX, Devereaux PJ, Yusuf S, Cuerden MS, Parikh CR, Coca SG, et al; CORONARY Investigators. Kidney function after off-pump or on-pump coronary artery bypass graft surgery. JAMA. 2014;311:2191-8.

9. Saija LR, Mannam G, Chakravarthi RM, Sompalli S, Naidu SK, Somaraju B, et al. Coronary artery bypass grafting with or without cardiopulmonary bypass in patients with preoperative non-dialysis dependent renal insufficiency: a randomized study. J Thorac Cardiovasc Surg. 2007;133:378-88.

10. Yu HY, Li JY, Sun S, Hung KY, Wang JL, Chen YS, et al. Late dialysis rate for coronary artery bypass grafting patients with moderate-to-severe renal impairment: comparison between off-pump and conventional method. Eur J Cardiothorac Surg. 2008;33:364-9.

11. Ueki C, Miyata H, Motomura N, Sakata R, Sakaguchi G, Akimoto T, et al; Japan Cardiovascular Surgery Database. Off-pump technique reduces surgical mortality after elective coronary artery bypass grafting in patients with preoperative renal failure. J Thorac Cardiovasc Surg. 2018;156:976-83. 